\title{
5 Marco REFERENCIAL PARA La EVALUACIÓN DE UN PROYECTO EDUCATIVO
}

\author{
Samuel Gento Palacios
}

Facultad de Educación

UNED. Madrid

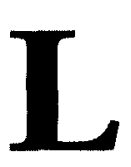

a evaluación es un componente ineludible de todo proyecto educativo que aspira a ser válido y eficaz. Esta evaluación ha de plantearse, en todo caso, con una finalidad esencialmente formativa, lo que implica que ha de llevarse a cabo con el propósito firme de utilizarla para mejorar los resultados, para optimizar el proceso de ejecución y, si fuera preciso, para reconsiderar los objetivos propuestos. Debe, pues, constituir un elemento potenciador del replanteamiento constante de todo el proyecto en sus diferentes fases. La evaluación de un proyecto puede entenderse como "un proceso sistemático, diseñado intencional y técnicamente, de recogida de información -valiosa y fiable- orientado a valorar la calidad y los logros del mismo, como base para la posterior toma de decisiones de mejora, tanto de dicho proyecto, como del personal implicado y, de modo indirecto, del cuerpo social en que se encuentra inmerso" (Pérez, R., 1995, pp. 85).

El análisis de los resultados, logrados o no, del proyecto debe hacerse teniendo en cuenta los objetivos planteados y debe conducir a la elaboración de las conclusiones y propuestas; estas últimas se orientarán al reforzamiento de los aciertos y a la modificación, si acaso, de los aspectos menos satisfactorios. En todo caso, ofrecerá una visión global del proyecto, así como el detalle pertinente de los aspectos específicos de los diferentes sectores, áreas y ámbitos concretos. 
La evaluación de un proyecto no debe, pues, constituir una acción puntual llevada a cabo en un solo momento de su gestión o desarrollo; por el contrario, ha de ser inherente al desarrollo del propio proyecto en sus diferentes fases y debe estar permanentemente presente desde antes, incluso, de su implantación. En realidad, pues, formará parte de cada una de las fases de desarrollo del proyecto, de modo que pueda analizarse cada una de ellas y pueda llegarse al reconocimiento de los factores o causas de los éxitos y de los fallos, así como de las posibles interacciones entre los mismos.

Pero, "para que la evaluación produzca efectos beneficiosos es preciso contar con la cooperación voluntariamente ejercida de los implicados en el proyecto; por el contrario, cuando se realiza contra la voluntad de aquéllos, nos encontramos ante el denominado "síndrome de Penélope", en el que, por no existir el necesario clima de confianza, la evaluación estará condenada al fracaso" (Plante, J., 1994, p. 50).

Aunque resulte difícil establecer un escalonamiento definido y preciso de las fases de evaluación de un proyecto, pueden considerarse, con carácter general, tres momentos prototípicos, a saber: inmediatamente después de su elaboración, pero antes de pasar a su aplicación; en su ejecución; y después de su realización. Con el fin de proceder a una cierta sistematización, siquiera por razones metodológicas, del conjunto del proceso de evaluación, consideraremos las tres acotaciones de temporalización siguientes: en la fase preactiva, previa a su aplicación; durante la fase interactiva o de explotación; y en la fase postactiva, una vez finalizada su aplicación (GENTO, S., 1995a, p. 185).

\section{VALIDACIÓN PREACTIVA}

Es aquélla que se realiza sobre la documentación que constituye el proyecto mismo, una vez finalizado el diseño, pero antes de su aplicación o realización. En este momento parece conveniente proceder a la validación del proyecto, con el fin de comprobar si efectivamente responde a lo que debe ser de acuerdo con la concepción teórica que se tiene del mismo: se trata, pues, de determinar el grado de adecuación de lo pretendido con lo realmente diseñado (Plante, J., 1994, pp. 19). En este sentido, podrían considerarse en esta fase evaluativa los siguientes tipos de validez: la de apariencia, de contenido, de constructo y de contraste (Gento, S., 1995a, pp. 185-7. Fig. 1).

\subsection{VALIDEZ DE APARIENCIA O APARENTE}

La validez de apariencia o aparente es la que se realiza a partir de la opinión de quienes han de manejar el proyecto diseñado, o que han de tomar 


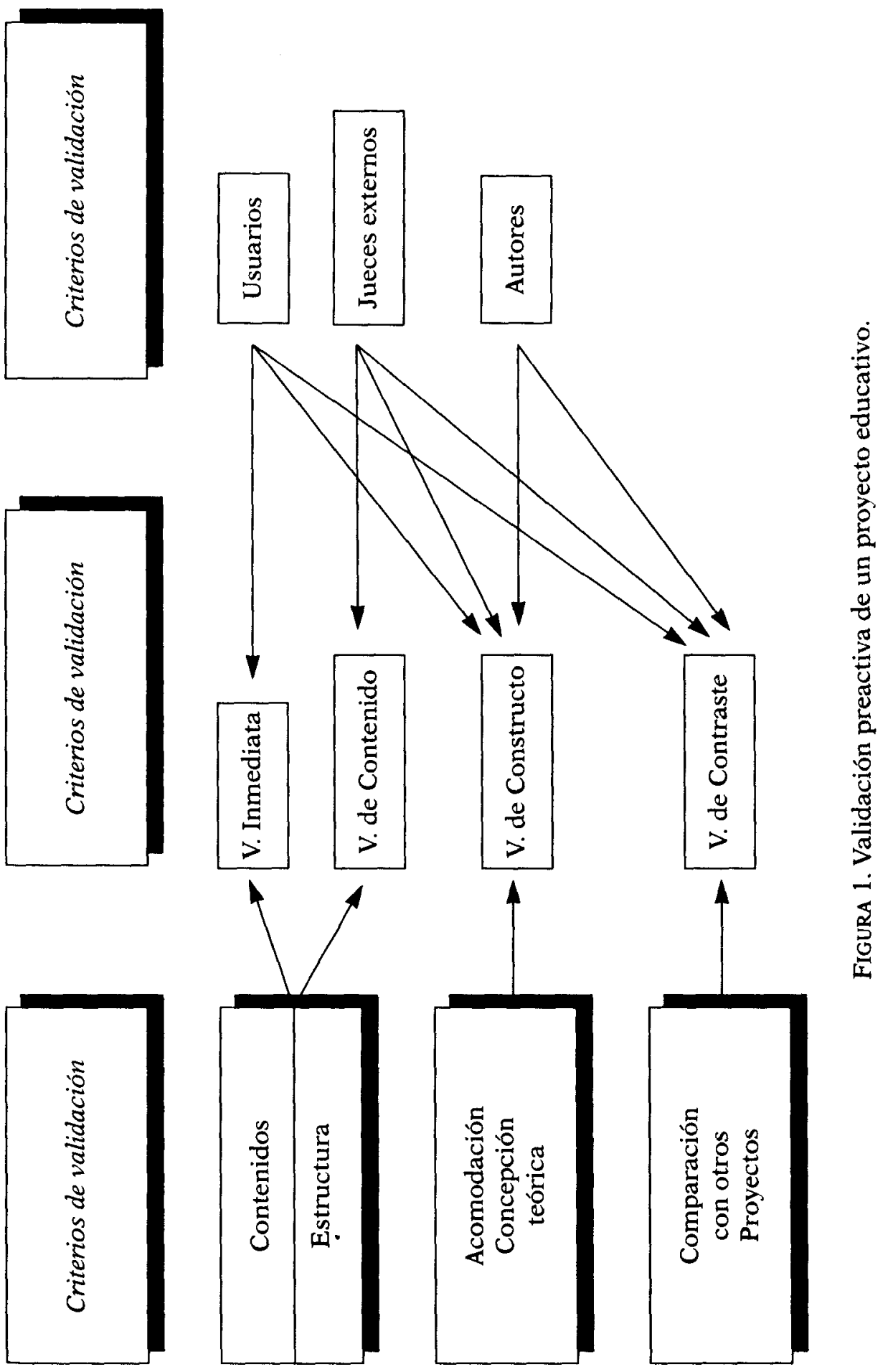


decisiones basadas en los resultados que se deriven de su ejecución (GENTO, S., 1989, pp. 103). Así, en un proyecto educativo podría preguntarse a los profesores y alumnos responsables de su realización, y también a directivos o personas con responsabilidad en las respectivas instituciones o programas.

Para obtener información que sirva para estimar la validez de apariencia o aparente habrá de recabarse la opinión estimativa de las mencionadas personas implicadas en su realización, utilizando para ello diferentes técnicas e instrumentos de evaluación (Gento, S., 1994b), entre ellos: cuestionarios, escalas de valoración, encuestas, entrevistas y otros.

Pero, para obtener información de utilidad relativa a la validez de apariencia o aparente, tendremos que recoger opiniones en torno a diversos criterios, tales como los siguientes: si constan en el proyecto todos los componentes que ha de tener; si, por el contrario, faltan algunos elementos fundamentales; si se acomodan a los requisitos necesarios que definen su calidad técnica (entre otros: claridad, objetividad, adecuación a la finalidad; viabilidad, exactitud o rigor conceptual); si están convenientemente estructurados en el orden preciso; si el proyecto y sus componentes son comprensibles; si se estima que ofrecen garantías de viabilidad; si su duración es la adecuada; si se define oportunamente a los responsables; etc.

Parece también que, además de ofrecer valoraciones ponderadas sobre los aspectos que se someten a estimación, las personas que opinen en esta evaluación de apariencia deben responder a cuestiones abiertas en las que puedan formular aportaciones sobre elementos a añadir o quitar, en su caso, reformulaciones, estructuración, etc.

\subsection{VALIDEZ DE CONTENIDO}

La validez de contenido trata de comprobar también la consistencia en el proyecto mismo de los elementos precisos con que debe contar. Pero, a diferencia de la de apariencia, la validación se obtiene aquí a partir de las aportaciones estimativas procedentes de jueces externos supuestamente expertos en la problemática que aborda el proyecto, o mediante la opinión de los propios realizadores del diseño, a quienes cabe considerar como expertos internos del proyecto mismo. La credibilidad de los jueces evitará la aparición del llamado "Efecto Blancanieves", que puede aparecer en aquéllos que se sienten mal valorados por la constatación de deficiencias del proyecto.

Para comprobar este tipo de validez pueden utilizarse instrumentos idénticos a los empleados para la de apariencia: en ellos se trata de recoger información facilitada por los expertos (internos o externos) en relación con la existencia en el proyecto de todos los elementos precisos y con la proporcionalidad convenientemente otorgada a cada uno de ellos. En todo caso, la esti- 
mación de dicha estructuración no debe agotarse con la simple apreciación, sino que irá acompañada de propuestas alternativas y de las justificaciones que las avalen. Algunos de los posibles contenidos sobre los cuales podría pedirse opinión en torno al grado de suficiencia y exactitud con que se tratan en el proyecto podrían ser los siguientes:

- Proceso de elaboración: considerará si en su elaboración ha existido una participación de los sectores implicados, particularmente profesores aunque también alumnos, y otros sectores; también podrá recogerse aquí si el proceso ha promovido actuaciones de trabajo en equipo; si se ha contado con asesoramiento especializado; si se ha consensuado su configuración con los implicados; etc.

- Fundamentación ideológico-conceptual: por ejemplo, modelo antropológico en que se basa, concepción pedagógica, marco jurídico-administrativo, ámbito institucional, etc.

- Contextualización: atendiendo a dimensiones de tipo sociopolítico, sociocultural y, en nuestro caso, socioeducativo.

- Acomodación al perfil psicopedagógico de los usuarios: en este sentido, cabría atender a la experiencia vital de los mismos, a sus necesidades, intereses, expectativas, motivaciones, etc.

- Componentes de calidad técnica del proyecto: aquí cabría referirse a la suficiencia o no con que se tratan los componentes necesarios, entre ellos, por ejemplo: los objetivos propuestos, los contenidos con los que se pretende lograrlos, la metodología a utilizar, las actividades previstas para su realización, la evaluación de resultados, los recursos a emplear, la temporalización y la previsión de evaluabilidad del proyecto.

Como posibles criterios de valoración que podrían emplearse, especialmente a la hora de ponderar los componentes que definen la calidad técnica de un proyecto, cabría citar: su viabilidad; su relevancia o trascendencia, su rentabilidad o dimensionalidad de sus efectos; inmediatez; eficacia; fuerza implicativa para los diversos agentes; actualidad; tratamiento equilibrado; rigor conceptual; claridad; etc. También podrían incluirse dentro de este tipo de validación de contenido las opiniones relativas a la estructuración u orden de los componentes que constituyen el proyecto.

\subsection{VALIDEZ DE CONSTRUCTO}

La validez de constructo pretende mostrar la acomodación del proyecto diseñado a la concepción teórica sobre la que se fundamenta: implica, por tanto, la valoración del ajuste de lo realizado con el modelo de diseño (bases filosóficas, antropológicas, sociológicas, psicopedagógicas, epistemológicas, etc.), con la concepción estructural del mismo y con la perspectiva de desarrollo. 
Aunque la apreciación de este tipo de validez puede ser más difícil que las anteriores, con ella se trata de evidenciar si el proyecto responde a la concepción teórica básica del modelo concebido. Para precisar adecuadamente esta validez de constructo podrían estructurarse los rasgos fundamentales que definen el modelo teórico que ha querido seguirse, valorándose posteriormente si aparecen y en qué medida en el proyecto elaborado.

También cabe incluir como integrante de la validez de constructo la atención al proceso de elaboración seguido para el diseño del proyecto; en este sentido, podría atenderse al seguimiento de las fases o etapas precisas, a la secuenciación debida, al grado de participación o implicación de las personas o sectores afectados por el proyecto, etc.

La apreciación de esta validez puede hacerse por los propios autores del proyecto, que realizan la autoevaluación del mismo mediante el contraste entre el arquetipo que tratan de realizar, comparado con la realidad palpable de lo que han hecho; para ello habrán de revisar el proyecto realizado y comprobar, entonces, su acoplamiento con el modelo concebido. También podría realizarse este tipo de validación previa por expertos conocedores del modelo, que actuarían en este caso como jueces externos. Cabe, incluso, plantear la posibilidad de que los propios usuarios del proyecto (en el ámbito educativo fundamentalmente profesores y alumnos) efectúen una validación de constructo, aunque, a tal efecto, se les debiera ofrecer algún instrumento que sea comprensible y fácilmente manejable por ellos.

\subsection{VALIDEZ DE CONTRASTE}

La validez de contraste trata de llevar a cabo una estimación de un proyecto estableciendo un parangón con otro u otros de similares características. Obviamente, el referente con el que se compare debiera ser uno que haya superado satisfactoriamente las valoraciones pertinentes y, en lo posible, que haya mostrado que funciona adecuadamente en su aplicación práctica.

Los descriptores señalados anteriormente para los tipos de validación a los que nos hemos referido pueden utilizarse, también, para comparar el diseño que se haya realizado con el modelo o prototipo. La validez de contraste puede llevarse a cabo por jueces externos; pero también pueden llevarla a cabo los propios autores del diseño e, incluso, aquellos que han de ejecutarlo. Con el fin de llevar a cabo la validación de modo objetivo y fiable, sería conveniente, también en este tipo, disponer de instrumentos que acrediten tales garantías. 


\section{EVALUACIÓN INTERACTIVA}

La evaluación interactiva se lleva a cabo durante la realización del proyecto educativo mismo, mediante la intervención colaborativa de los responsables de su ejecución. La experiencia reflexiva y contrastada, que constituye una actitud evaluativa continuada de las fases y componentes de un proyecto, supone un elemento enriquecedor de gran alcance, tanto para el proyecto mismo, como para los que participan en dicha experiencia (en especial, para los responsables de su puesta en acción).

La implantación del proyecto puede requerir adaptaciones para acomodarlo a la propia realidad o a las circunstancias que aparezcan y que no pudieron ser previstas. Pero, sin perjuicio de tal eventualidad, el diseño efectuado servirá de guía en la ejecución y se utilizará como referencia para la valoración del proceso.

La responsabilidad última sobre el control del desarrollo del proyecto corresponderá a la dirección del mismo; pero ésta podrá delegar el seguimiento y control específico de determinados aspectos en las comisiones que resulten más apropiadas o en quienes puedan desempeñar eficazmente tal cometido que, en todo caso, trasladarán la información recogida a dichas comisiones.

La valoración del proyecto durante la fase de su ejecución puede hacerse teniendo en cuenta diversos criterios, que habrán de definirse previamente. Algunos de tales criterios pueden ser su ajuste con lo planificado, considerando a tal efecto si el desarrollo se acomoda a lo previsto o si ha habido retraso o anticipación; también puede comprobarse si durante el desarrollo del proyecto han aparecido algunos resultados no previstos; otro aspecto, de extraordinaria importancia en un proyecto educativo, será la satisfacción de los implicados que intervienen en su ejecución (por los materiales utilizados, por el clima de trabajo, por la metodología empleada, por las actividades desarrolladas, etc.).

En la evaluación interactiva pueden utilizarse diversos procedimientos, técnicas e instrumentos, cuyo uso dependerá de la situación y de los condicionamientos de cada caso (Gento, S., 1994c, pp. 382-3. Fig. 2). Muchos de estos tipos podrán también manejarse luego, en la evaluación postactiva, además de poder utilizarse en la evaluación que lleven a cabo los profesores con sus alumnos y en las aulas.

Aunque no siempre los términos anteriormente mencionados se manejan con todo rigor $y$, en ocasiones, hasta se utilizan indistintamente con significado equivalente, debe entenderse que, en el ámbito de la evaluación, un procedimiento es el modo o método específico y estructurado de operativizar los pasos necesarios para llegar a la valoración de aquello que es objeto de evalua- 


\begin{tabular}{|c|c|c|}
\hline Procedimientos & Técnicas & Instrumentos \\
\hline $\begin{array}{l}\text { Autoevaluación } \\
\text { Heteroevaluación }\end{array}$ & $\begin{array}{l}\text { Observación: } \\
\text { - Etnografía. } \\
\text { - Participante. } \\
\text { - No participante. } \\
\text { - De instalaciones, } \\
\text { materiales } \\
\text { y resultados. }\end{array}$ & $\begin{array}{l}\text { - Guías de evaluación. } \\
\text { - Inventarios. } \\
\text { - Listas de cotejo o control. } \\
\text { - Anecdotarios. } \\
\text { - Diarios (cuadernos de } \\
\text { campo). } \\
\text { - Rejillas. } \\
\text { - Estudio de casos. } \\
\text { - Análisis de contenido. } \\
\text { - Análisis de trabajos. } \\
\text { - Análisis de tareas. } \\
\text { - Escalas de observación. }\end{array}$ \\
\hline Coevaluación & $\begin{array}{l}\text { Interrogativas: } \\
\text { - Orales. }\end{array}$ & $\begin{array}{l}\text { - Exámenes orales. } \\
\text { - Entrevistas. }\end{array}$ \\
\hline Triangulación & $\begin{array}{l}\text { Interrogativas: } \\
\text { - Escritas. }\end{array}$ & $\begin{array}{l}\text { - Cuestionarios. } \\
\text { - Escalas de evaluación. } \\
\text { - Pruebas sociométricas. } \\
\text { - Memorandos. } \\
\text { - Informes. } \\
\text { - Tests estandarizados. } \\
\text { - Pruebas objetivas. } \\
\text { - Exámenes tradicionales } \\
\text { - Autobiografías. }\end{array}$ \\
\hline
\end{tabular}

Figura 2. Técnicas, procedimientos e instrumentos de evaluación. 
ción. Implica, por tanto, una forma o modo determinado de actuación en este campo y, en cierto modo, nos sitúa ante un enfoque conceptual de dicho modo de actuación peculiar. Los procedimientos básicos de actuación, cuya utilización es posible en la valoración de planes o proyectos educativos, son los siguientes: autoevaluación, heteroevaluación, coevaluación y triangulación.

\section{Técnicas de evaluación}

Una técnica supone, por su parte, el acopio de recursos y la realización de procesos que conduzcan a la consecución más eficaz, eficiente y cómoda posible del objetivo o meta perseguida. En tal sentido, requiere que se actúe de acuerdo a unos criterios y modos de actuación perfectamente definidos y contrastados, para garantizar la consecución del propósito perseguido en las mejores condiciones posibles, siempre que se actúe de acuerdo con las especificaciones de dicha técnica. En el ámbito propio en que nos situamos, una técnica de evaluación hace referencia a una actuación sistemáticamente organizada y estandarizada, para garantizar el éxito en la obtención de una valoración del modo más rentable posible.

Para conseguirlo, la técnica trata, mediante procesos de actuación peculiares, de controlar el error, de reducir el costo y de lograr una definición valorativa con la mejor utilización de los recursos y la máxima satisfacción de los implicados. Ya se trate de técnicas de evaluación que respondan a paradigmas de tipo cuantitativo, o que se acojan al de índole cualitativo, la propia condición de dichas técnicas exige para su credibilidad que se sometan a las garantías de rigor científico en cada caso (Castillo, S. y Gento, S., 1995 , pp. $31-2 ; 36-7)$.

Básicamente, las técnicas evaluativas pueden reducirse a dos, a saber: la de observación y la de tipo interrogativo. Pero la experiencia que va acumulándose en torno a la utilización de las mismas va haciendo surgir diversas modalidades de utilización de una y otra, con lo que cabría distinguir, de un lado, entre técnicas interrogativas orales y escritas y, de otro, entre las de observación de carácter no participante, participante, etnográfica, o de instalaciones, materiales y resultados.

Tal como hemos señalado anteriormente, la técnica implica el sometimiento a parámetros de sistematización, estandarización y contraste, orientados a la mayor eficacia, eficiencia y satisfacción de los implicados. La necesidad de utilizar diversas técnicas para garantizar, así, la consistencia de la evaluación efectuada procede de diversas causas, a saber: la necesidad de complementar y contrastar la información que puedan ofrecer, en su caso, diferentes evaluadores; la limitación de los propios instrumentos de medida; 
y la diversidad de los aspectos que conviene valorar, que pueden requerir diferencias en el modo de apreciación de los mismos.

Las técnicas de observación nos sitúan ante la recogida de información sobre situaciones o procesos en el momento en que se producen, generalmente de modo natural (sin provocación externa) y por alguien ajeno a los mismos (salvo en el caso de la autoobservación). Para que la observación resulte de utilidad se requiere una especial predisposición para percibir la realidad tal como se presenta y, además, agudeza para explorar en lo observado, de modo que pueda llegarse a captar el sentido de la realidad o lo que sucede. De este modo, la percepción y reflexión atenta de una realidad o de un proceso permite identificarlo de modo auténtico y en su verdadero significado.

Pero la observación implica un riesgo de "subjetivismo" en la valoración que realiza el observador, particularmente cuando interpreta hechos o acontecimientos. Para eliminar la arbitrariedad del subjetivismo, el observador ha de adoptar un equilibrado distanciamiento; de este modo, evitará la falta de conocimiento del contexto, así como la excesiva implicación; también puede obviarse el riesgo de subjetividad mediante el contraste de los resultados de la observación realizada por diversos evaluadores. Otros requisitos que debiera reunir la observación para garantizar su fiabilidad y consistencia científica serían los siguientes: la naturalidad, que permita la recogida de situaciones que se desarrollan espontáneamente, y la intencionalidad en la atención a los acontecimientos, lo que requerirá una seria planificación de los aspectos a evaluar.

La utilización de la técnica de observación está propiciando la aparición de modalidades de la misma. Así, la observación etnográfica pretende recoger no tanto los acontecimientos mismos, cuanto la interpretación que los sujetos humanos o los grupos de ellos otorgan a situaciones concretas; claro que tales interpretaciones obedecerán frecuentemente al propio referente cultural, en virtud del cual efectuarán el filtro de lo que perciben a través de los sentidos. Algunos supuestos que conviene tener particularmente en cuenta a la hora de realizar esta modalidad de observación son los siguientes (Santos, M.A., 1990, pp. 46-50): enfatizar el valor de los intercambios psicosociales de sus elementos personales, subrayar el valor de los procesos, utilizar la opinión de los protagonistas, dar prioridad a los aspectos cualitativos de la evaluación, y promover la autorreflexión sistemática y rigurosa.

La observación participante supone que el agente evaluador se integre en la propia situación, compartiendo incluso el protagonismo de las actuaciones y aspectos que van a valorarse. Para ello, el observador participante, que en ningún caso deberá obstruir o perturbar la marcha del proyecto, habrá de sumergirse en el grupo y en el ámbito a evaluar sin preconceptos; por el contrario, tratará de observar la realidad de modo incontaminado, tal cual surge 
de las actuaciones y circunstancias. Pero, para que el evaluador participante pueda ser oportunamente aceptado por el grupo de personas responsables del proyecto o proceso en cuestión, habrá de llevar a cabo previamente con éstas la negociación que desemboque en su aceptación y en la ubicación de su propio nicho de responsabilidad.

Diferenciamos la observación participante de la no participante, ya que esta última se realiza sin la inmersión en la responsabilidad del desarrollo del proyecto de que se trate. También consideramos aparte la observación de instalaciones, materiales o resultados, por entender que no aluden propiamente a la estimación de procesos en marcha, típicos de la evaluación interactiva.

Otro tipo de técnicas evaluativas son, precisamente, las que hemos denominado como interrogativas. Son aquéllas en las que la evaluación se realiza sobre la información que ofrecen los individuos o grupos objeto de indagación evaluativa, a través de instrumentos en los que son preguntados, de forma directa o indirecta, sobre aquellos aspectos que hacen relación al tema evaluado (Gento, S., 1994b, p. 388). Claro que puede ocurrir que la interrogación se produzca por agentes externos (en cuyo caso nos encontramos con el procedimiento de la evaluación externa o heteroevaluación), o por los sujetos implicados que se someten a sus propias preguntas (y entonces nos situaríamos dentro del procedimiento de autoevaluación o evaluación interna).

Si la interrogación se lleva a cabo a través de la comunicación hablada, nos encontramos ante la utilización de técnicas interrogativas orales. Pero, si lo que se maneja son preguntas y respuestas de escritura, tendremos que hablar de técnicas interrogativas escritas. Cabe, incluso, considerar técnicas interrogativas gráficas, si lo que se utiliza son símbolos de carácter icónico; pero, a efectos de simplificación, incluimos las dos últimas dentro de un mismo tipo, en el que situamos tanto la utilización de símbolos lingüísticos como los de tipo icónico.

\section{Instrumentos de evaluación}

Cuando los procedimientos y las técnicas tratan de ponerse en acción surge la necesidad de contar con elementos materiales o concreciones operativas que sirvan de mediación para lograr el propósito perseguido. Y aquí es, precisamente, donde surge la necesidad y la utilidad de los instrumentos, en tanto que recursos operativos o materiales de uso cuya utilización es precisa para la puesta en práctica de una técnica o de un procedimiento. El instrumento supone, por tanto, el máximo nivel de concreción, tanto referido a los materiales a utilizar, como a las acciones a realizar. 
En el ámbito propio al que aquí nos referimos, un instrumento de evaluación hace, pues, referencia a cualquier material de uso o modo concreto de actuación que pueda ser convenientemente utilizado para la recogida, contrastación y acopio de la información precisa para conducir a la valoración propuesta, dentro de una perspectiva educativa. Para la operativización de las técnicas evaluativas que hemos descrito, se utilizarán los instrumentos que mejor se acomoden a las mismas. Algunos de los que cabe manejar cuando se utilizan técnicas de observación son los siguientes:

- Guías de evaluación (como planificaciones organizadas que orientan el proceso evaluativo).

- Inventarios (que relacionan la existencia o aparición de elementos o aspectos que figuran en ellas).

- Listas de cotejo o control (también conocidas como "listas de punteo o verificación", en las que se recogen datos o aspectos siguiendo un listado ya establecido).

- Anecdotarios (llamados, también "fichas anecdóticas" o, asimismo, "registros de anécdotas, de incidencias o de hechos significativos", recogen el relato de circunstancias o situaciones significativas. El registro puede ser de carácter escrito, sonoro, visual fijo o móvil, o audiovisual).

- Diarios (llamados, también, "cuadernos de campo", permiten recoger la descripción de determinados procesos o actuaciones en su totalidad. Pueden ser tanto del profesor como de los propios alumnos).

- Rejillas (también denominadas "matrices", permiten valorar hechos o situaciones mediante la utilización de documentos normalizados en los que figuran dos tipos de categorías; en las filas generalmente el tema o hecho a valorar, y en las columnas las categorías de evaluación).

- Estudio de casos (en ellos se recogen datos y posibles soluciones a adoptar ante problemas o situaciones cuyo relato se describe previamente).

- Análisis de contenido (se recoge información valorativa en torno a documentos que se han analizado, por ejemplo, el Proyecto Educativo de un centro determinado).

- Análisis de trabajos (o "análisis de producciones"; en ellos se lleva a cabo la valoración de las producciones realizadas, tales como una composición escrita o una maqueta realizada).

- Análisis de tareas (aluden a la evaluación que se lleva a cabo de los procesos o actividades que se han realizado dentro de un proyecto o cometido llevado a cabo).

- Escalas de observación (llamadas, también, a veces "de estimación o de valoración", se utilizan para la ponderación de rasgos o aspectos determinados, utilizando para ello estimaciones numéricas, verbales o descriptivas). 
Entre los instrumentos que cabe manejar para la utilización de técnicas interrogativas orales cabe referirse a los exámenes orales y a las entrevistas. En aquéllos el examinador puede acomodarse con mayor facilidad a la peculiaridad de la persona evaluada y a las circunstancias de cada situación; pero, en cambio, ofrecen mayor riesgo de subjetividad en la valoración.

En las entrevistas la persona o personas sometidas a valoración responden a las preguntas que formula el entrevistador. Pero la entrevista como instrumento evaluativo de carácter oral puede adoptar varios tipos, según el modo en que se realice. Así, cabe hablar de entrevistas "libres", cuando no se maneja un guión o listado previo de preguntas. En las entrevistas "estructuradas" existe ese guión y las preguntas a formular previamente a la realización de dicha entrevista. En la entrevista "semiestructurada" se da una combinación de las dos anteriores (aunque existe un guión previo y, tal vez, algunas preguntas predeterminadas, el entrevistador puede modificar el esquema inicial $o$ introducir algunas cuestiones durante el desarrollo de la entrevista).

Puede, también, hablarse de entrevistas "grupales" cuando las preguntas se dirigen a diversas personas que se encuentran formando parte de un grupo durante la realización de tal entrevista. En las de tipo "formal" suele seguirse un esquema o diseño previo muy ajustado a la temática a tratar. Por el contrario, en las entrevistas de tipo "informal" las preguntas surgen espontáneamente en un clima distendido y sin necesidad de seguir rigurosamente un esquema previo.

Cuando lo que se pretende es llevar a cabo técnicas de evaluación de tipo interrogativo, pueden utilizarse instrumentos que respondan a este peculiar modo o uso concreto. En tal caso, cabe referirse a los instrumentos siguientes:

- Cuestionarios (serie de preguntas escritas a las que responden las personas evaluadas. Pueden ser de carácter cerrado, cuando de lo que se trata es de elegir una o varias respuestas ya elaboradas; abierto, si la respuesta ha de ser elaborada por quien cumplimenta el cuestionario; 0 mixto, cuando incluye rasgos de uno y de otro).

- Escalas de evaluación (similares a los cuestionarios, pero en las que la respuesta escrita supone una valoración, que se lleva a cabo utilizando para ello diversas categorías numéricas o verbales previamente establecidas).

- Pruebas sociométricas (instrumento evaluativo realizado a partir de preguntas destinadas a medir las interacciones sociales y para mostrar la configuración de las relaciones entre los miembros de un grupo determinado).

- Memorandos (suponen la existencia de un instrumento guía para la realización de un proceso de evaluación de cierta complejidad, tal como la 
auditoría. Pueden incluir, entre otros aspectos, los elementos a valorar, los objetivos de cada evaluación, los controles a efectuar, la validez interna de los controles, etc.).

- Informes (descripción detallada que realiza un experto de las evidencias detectadas y de la valoración de las mismas).

- Tests estandarizados (construidos por expertos, con ellos se pondera el valor de los resultados en base a baremos contrastados para diversos grupos de población).

- Pruebas objetivas (en ellas la valoración se hace de acuerdo a criterios objetivos que se aplican a preguntas cuyas respuestas han sido previamente fijadas).

- Exámenes tradicionales (se constituyen a base de pruebas de ensayo o temas abiertos - que pueden ser extensos o breves- y adoptan a veces la forma de problemas, traducciones, comentarios de texto $u$ otras modalidades que requieren una elaboración de cierta intensidad a cargo de la persona evaluada).

- Autobiografías personales (conocidas, también como "curriculum vitae", recogen la experiencia profesional acumulada por una persona, frecuentemente referida a un ámbito de actividad profesional determinada).

Por su especial relevancia en la evaluación de un proyecto educativo, desarrollaremos seguidamente de modo separado los procedimientos de evaluación del mismo.

\subsection{AUTOEVALUACIÓN}

Entre los posibles procedimientos de evaluación a utilizar que tienen aplicación en esta fase interactiva, cabe referirse a la autoevaluación (que se lleva a cabo por los propios implicados; en el caso de un centro educativo, pueden fundamentalmente ser los profesores y alumnos, además de los directivos, padres y otros profesionales que constituyen dicho centro). En ocasiones, este procedimiento recibe la denominación de "evaluación interna", dado que se realiza por los propios sujetos evaluados y en virtud de su propia iniciativa.

En el ámbito de las instituciones educativas, la autoevaluación pretende especialmente la mejora de la profesionalización de los docentes y del funcionamiento general de los centros. Pero la aportación más relevante de este procedimiento de evaluación es, precisamente, el incremento del potencial de autoanálisis que desarrolla entre los implicados, particularmente entre los docentes. Asimismo, se desarrolla también en quienes se autoevalúan la habilidad para valorar con más exactitud su propia actuación y los resulta- 
dos alcanzados. La importancia de este procedimiento resulta cada vez más evidente, considerándose que la autoevaluación es un promotor fundamental de la mejora, mucho más relevante que la heteroevaluación: "El control autogenerado de la calidad es mucho más eficaz que la calidad del control llevado por la inspección externa" (Peters, T.J. \& Waterman, R.H., 1993, p. 29).

Para que la autoevaluación sea efectiva será preciso contar con la aceptación y el apoyo de los directivos del centro, además de la de los propios profesores; pero, además, habrá ocasiones en las que deberá contarse también con la intervención de los alumnos y hasta de los padres de los mismos en la medida que corresponda (esto último, especialmente en los niveles básicos del sistema educativo no universitario). En definitiva, todos los sectores implicados habrán de comprometerse con esta autoevaluación, como medio para mejorar el funcionamiento y los resultados, de acuerdo con el proyecto diseñado. Pero, para que la implicación voluntaria de los sectores afectados se fortalezca, resultará conveniente consensuar la forma y contenido de la autoevaluación.

\subsection{HETEROEVALUACIÓN}

Otro procedimiento de posible utilización es el de la heteroevaluación o evaluación externa (que realizan personas ajenas al centro, por ejemplo, la que lleva a cabo la Inspección educativa). En este procedimiento la estimación es realizada, generalmente, por profesionales que no forman parte de la estructura de la institución, y a los que se otorga cierta autoridad como jueces expertos.

Por llevarse a cabo por agentes externos, a quienes se les supone una autoridad o preparación técnica para la tarea, parece que su actuación y juicios valorativos puedan tener más independencia; sin embargo, su falta de conocimiento del contexto y de las necesidades de la institución en la que actúan puede dificultar una percepción adecuada de la realidad. Parece, en todo caso, que tales expertos evaluadores externos han de ser conocedores de la educación. Deben, además, formar un equipo homogéneo, que actúe con honestidad y con autonomía de criterio. Además de ello, han de utilizar técnicas e instrumentos que sean fiables y que faciliten información con las garantías precisas.

Para que la evaluación externa tenga un efecto estimulador sobre la institución, sobre los miembros de la misma y sobre el proyecto educativo cuya valoración se realice, parece conveniente que se lleve a cabo, a ser posible, a solicitud de la propia institución y de modo consensuado con ella. Se planteará, además, como una experiencia enriquecedora para la institución, implicará la participación activa de los propios implicados y garantizará el uso con- 
veniente de la información obtenida (que, en algunos casos, podrá ser confidencial o reservada).

De acuerdo con los requerimientos señalados, la tendencia predominante en la actualidad (especialmente cuando se evalúan instituciones, su funcionamiento, o sus planes o proyectos de actuación) es considerar básica la autoevaluación o evaluación interna. Es, precisamente, sobre ésta y con el propósito de garantizar la consistencia técnico-científica de tal evaluación, como se llevará a cabo la evaluación externa o heteroevaluación; la conjunción de ambos procedimientos habrá de suscitar un consenso y requerirá, en última instancia, la aceptación del dictamen final por los implicados como algo propio. Es posible, incluso, que la redacción definitiva del informe en el que conste el dictamen final deba hacerse por tales implicados o, caso de hacerlo los evaluadores externos, al menos con la intervención de los autoevaluadores.

\subsection{COEVALUACIÓN}

Otro procedimiento lo constituye la coevaluación (que se realiza conjuntamente por varios sectores: así, por ejemplo, la que puedan realizar los alumnos y el profesor conjuntamente, o los propios alumnos de los aspectos que a ellos mismos les afectan). En definitiva, se trata de llevar a cabo procesos valorativos de forma que participen en los mismos tanto aquéllos que son objeto de estimación, como otras personas no comprometidas con aquello que se evalúa. Así entendida, la coevaluación resulta ser un procedimiento en el que la multiplicación de los agentes externos e internos que participan en la evaluación constituye una garantía máxima de corresponsabilidad.

Puesto que la optimización de los procesos docentes y educativos requiere, en todo caso, la concurrencia del propósito de los profesores, la iniciativa en la dinamización de un procedimiento de coevaluación parece que debe corresponder a estos últimos. Los evaluadores externos, por su parte, han de estar a disposición de todo el personal de la institución, ofreciéndoles su experiencia y los instrumentos necesarios para llevar a cabo la evaluación con garantías de rigor científico y que responda a las necesidades manifestadas.

La dinamización de equipos mixtos de evaluadores externos e internos debe poner en acción técnicas participativas de colaboración que conduzcan a la asunción conjunta y compartida de responsabilidades evaluativas. Es, precisamente, la implicación en la decisión lo que constituye el máximo exponente de la participación y la mejor garantía de compromiso para colaborar en el logro de los propósitos fijados, es decir, en las acciones de mejora.

El procedimiento de coevaluación puede adoptar diversas modalidades. Así, puede ser llevada a cabo conjuntamente por el profesor y sus alumnos; 
por los propios alumnos entre sí; por profesores, alumnos y padres; por profesores y directivos del centro; por profesores, directivos e inspectores o supervisores; o adoptando otras composiciones.

\subsection{TRIANGULACIÓN}

Finalmente, el procedimiento de la triangulación permite contrastar diferentes perspectivas evaluativas sobre un mismo hecho o fenómeno (Santos, M. A., 1990). Se utiliza para establecer contrastes desde diferentes enfoques, para apreciar acuerdos o desacuerdos, y para precisar elementos que permitan decidir sobre la credibilidad de la información. En virtud del mismo, diversos sectores o personas valoran los mismos supuestos en situaciones sucesivas o simultáneas. Posteriormente, deben compararse los resultados que cada uno de los responsables de evaluación ha obtenido, al objeto de extraer las conclusiones más válidas y fiables.

La definición clásica de la triangulación aportada por Denzin, N. (1978), la considera como "la combinación de metodologías en el estudio del mismo fenómeno". El procedimiento pretende eliminar la subjetividad apreciativa basada en un solo individuo u observador, así como el sesgo que puede suponer la utilización de una única fuente de evaluación.

Pero este procedimiento admite diversos enfoques (Santos, M., 1990, pp. 116-121): triangulación de métodos (mediante la utilización de diversos procedimientos), triangulación de sujetos (contrastando los diferentes puntos de vista de los distintos sujetos en la exploración), triangulación de momentos (exploración en diversos ángulos temporales), triangulación de expertos (contraste de opiniones de evaluadores expertos, ajenos al proyecto, y miembros activos del mismo).

En ocasiones, la triangulación se basará en el contraste de datos obtenidos por diferentes fuentes o por la utilización de distintos métodos. En otros casos, puede fundarse en la contrastación de los datos obtenidos por los distintos miembros de un equipo de evaluación. Cuando éstos hayan obtenido sus datos y llegado a sus propios resultados, se pondrán en común para determinar las coincidencias, que ratifiquen la información, o las discrepancias, que deberán aclararse o analizarse de nuevo, en su caso.

Para la ejecución de los procedimientos que acabamos de mencionar, pueden utilizarse diferentes técnicas evaluativas. Como posibles técnicas de evaluación a utilizar cabe referirse a la observación en sus diversas modalidades (etnográfica, participante, no participante, o de instalaciones, materiales y recursos). También pueden manejarse otras de tipo interrogativo: éstas pueden ser orales o escritas. 
La realización de la evaluación interactiva implica una oportunidad extraordinariamente eficaz para la consolidación de una síntesis profesional superadora de la dialéctica entre teoría y práctica, que se conjugan en un intento de fusión sublimador; el autoanálisis de la práctica y la continua reflexión sobre la teoría deben, pues, conjugarse de un modo funcionalmente operativo. Se trata, por un lado, de reflexionar sobre las aportaciones que la teoría supone para la práctica; pero, además, de partir del análisis de la práctica como referente inicial para lograr una teoría generalizadora sobre la misma. Fruto de esta experiencia reflexiva podría ser la elaboración de la memoria de contraste, que refleje la diferencia entre lo previsto y lo practicado.

De todos modos, para el establecimiento de una cultura evaluativa en las instituciones educativas pueden emplearse recursos tales como los siguientes (Scheerens, J., 1992, p. 90):

- Utilizando materiales didácticos y libros que lleven incorporada la evaluación: esta estructura aparece frecuentemente en los materiales didácticos elaborados por la UNED para su explotación por alumnos a distancia.

- Empleando pruebas estandarizadas de rendimiento escolar que permitan establecer comparaciones con los resultados obtenidos por los alumnos.

- Haciendo uso de bancos de datos, sistemas de evaluación y de información sobre la gestión educativa.

- Institucionalizando conversaciones y reuniones del director con los profesores e, incluso, con los alumnos y hasta con los padres, para tratar sobre la eficacia de la enseñanza.

- Potenciando el manejo de instrumentos de autoevaluación, tanto para los alumnos (a fin de que comprueben su desarrollo), como para los profesores (para que puedan valorar los resultados de su intervención educativa, empleo de metodologías y materiales, etc.).

- Estableciendo los requisitos organizativos necesarios mínimos para la realización y explotación de la evaluación, como por ejemplo: reuniones periódicas entre los profesores a través de los equipos o departamentos docentes dentro del centro.

Pero, además de la autoevaluación que realizan los propios profesionales responsables de le ejecución del proyecto, vale la pena también considerar las aportaciones estimativas que realicen otros implicados en el mismo. Ya se trate de técnicas de evaluación que respondan a paradigmas de tipo cuantitativo, o que se acojan al de índole cualitativo, la propia condición de dichas técnicas exige para su credibilidad que se sometan a las garantías de rigor científico en cada caso (Castillo, S. y Gento, S., 1995, pp. 31-2; 36-7). Para este propósito podría emplearse la recogida de opiniones personales, o podrían utilizarse técnicas de autoanálisis o heteroanálisis grupal. 
El autoanálisis grupal supone una práctica colaborativa de investigación acción de enorme fuerza enriquecedora para los que la realizan. Se trata, en definitiva, de comprobar de modo conjunto la propia ejecución del proyecto, la adecuación y la coordinación de todos los componentes (Medina, A. y Gento, S., 1991, pp. 104). En el heteroanálisis grupal la reflexión colaborativa de la acción práctica debe permitir, debidamente canalizada, una aportación comprometida que conduzca a valoraciones y propuestas en las que los distintos miembros se sientan responsablemente implicados.

En el nivel más concreto de operativización evaluativa, los procedimientos y técnicas se ponen en acción mediante instrumentos de evaluación. Éstos se refieren a "materiales o modos concretos de presentación que pueden ser convenientemente utilizados para la recogida, contraste y acopio de la información precisa que conduzca a la valoración". Para la determinación de las garantías de rigor científico de tales instrumentos, habrán de precisarse los coeficientes de fiabilidad de los mismos.

Para recoger información a partir de una técnica evaluativa de observación, en sus diversas modalidades, pueden utilizarse diversos instrumentos, entre los que cabe mencionar los siguientes: guías de evaluación, inventarios (de comportamiento, de intereses, percepciones, sentimientos, etc.), listas de cotejo o control, anecdotarios o registros de anécdotas, registros (de incidencias por escrito, grabaciones o filmaciones de situaciones reales), diarios o cuadernos de campo (del profesor, del alumno, del aula), rejillas, estudio de casos, análisis de contenido, análisis de producciones o trabajos realizados, análisis de tareas, o escalas de observación.

Instrumentos propios de las técnicas de tipo interrogativo oral serían las entrevistas en sus diversas modalidades (libre, estructurada o semiestructurada) y los exámenes orales.

Como instrumentos a utilizar dentro de las técnicas de tipo interrogativo escrito cabría referirse a las siguientes: cuestionarios, escalas de evaluación, pruebas sociométricas, memorandos, informes, tests estandarizados, cuestionarios, pruebas objetivas, exámenes tradicionales, o autobiografías.

Como criterios posibles de valoración podría atenderse al ajuste a la planificación y su inserción en el contexto. El primero de ellos podría considerar: la temporalización, la secuenciación, y la flexibilidad en la aplicación. La inserción contextual, por sụ parte, podría atender a la estimación de: el clima institucional (dentro del mismo, la satisfacción del personal por el proceso, el grado de participación de individuos o sectores implicados, las actividades, etc.), la coherencia institucional (del proyecto con otros proyectos o marcos rectores de la institución), el clima social, la utilización de los recursos, etc. 


\section{VALORACIÓN POSTACTIVA}

Evaluación postactiva es aquélla que se lleva a cabo una vez concluida la aplicación del proyecto. La integración de los datos recogidos en esta evaluación postactiva o "postfacto" conducirá a la elaboración de las conclusiones pertinentes sobre el proyecto, para las que se tendrán en cuenta las evidencias puestas de manifiesto. Parece, además, conveniente que esta fase evaluativa finalice con una "propuesta fundamentada", en la que se formulen las sugerencias para el funcionamiento futuro del proyecto. El análisis de los resultados, propio de esta fase postactiva, podría contemplar los descriptores que se exponen a continuación (Gento, S., 1989; Medina, A. y Gento, S., 1991. Fig. 3).

\subsection{INDICADORES DE EFICACIA}

La medición de la calidad resulta especialmente difícil en las empresas o instituciones orientadas a la provisión de servicios (Peters, T.J. \& Waterman, R.H., 1993, p. XIX). Los centros educativos caen de lleno dentro de este grupo de organizaciones, por lo que hemos de tener en cuenta la especial dificultad que supone la evaluación en los mismos. Ello no debe, sin embargo, llevarnos a eludir el esfuerzo necesario para lograrlo.

Los indicadores de eficacia tratan de llegar a una estimación de los resultados conseguidos o productos logrados, aunque sin plantearse la repercusión que sobre los mismos hayan podido tener los elementos que constituyen el "input" (básicamente, el contexto y recursos). Ello implica, por tanto, la valoración de si se han conseguido los objetivos o metas previstos y en qué medida, tanto en cantidad como en calidad y en tiempo previsto.

Cabría, por tanto, incluir aquí la ponderación de los éxitos logrados, los fracasos y las carencias o deficiencias, todo ello en función de la previsión realizada. Estos resultados podrán analizarse en relación con una referencia normativa (en la que se tendrán en cuenta baremos establecidos al margen del proyecto por autoridades externas al mismo), o con referencia criterial (en la que se atendrán a los objetivos planteados en el propio proyecto).

Entre los indicadores de eficacia podrían incluirse aspectos como los siguientes: éxitos logrados (objetivos cumplidos), carencias apreciadas (objetivos no logrados), deficiencias acaecidas, malfuncionamientos ocurridos, satisfacción con los proveedores (en el sistema educativo, podrían ser los niveles o etapas previos), satisfacción de los clientes externos (alumnos) y de los internos (personal del centro), proyecto de formación de personal, y otros. Pero, además del análisis de los resultados referidos a los objetivos programados previamente, la evaluación postactiva podría entrar en la consideración de los efectos no previstos. Estos efectos, que podrían ser desea- 


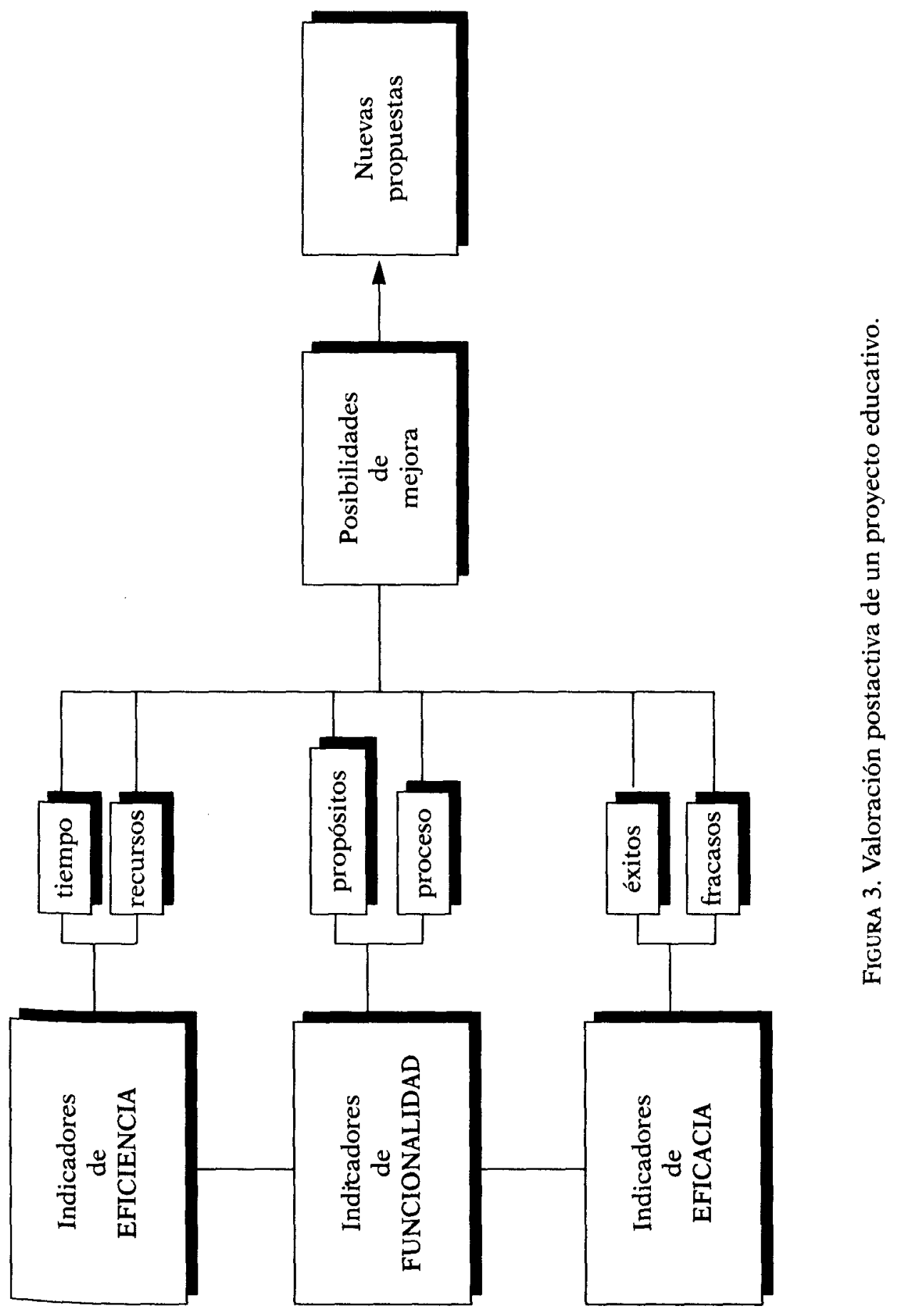


bles o no, suelen aparecer con frecuencia y relevancia suficiente como para merecer ser tenidos en cuenta en dicha evaluación "postfacto".

En relación con la determinación de los indicadores no faltan autores que muestran la dificultad de la misma. Así, Santos, M.A. (1990, pp. 58-59) señala que "someter los indicadores de calidad de un centro educativo a un principio estructurador u organizador es difícil, ya que cualquiera que se elija resultará insuficiente e impreciso. No hay fronteras claras entre funciones, estructura, valores y medios".

Antes, sin embargo, de la determinación y, sobre todo, ponderación de los indicadores, es preciso definir el modelo de referencia por el que se opta y la estructura básica del mismo; a partir de ahí puede iniciarse la tarea de determinar los indicadores y trabajar en la estructuración ponderada de los mismos.

En cuanto a los responsables de la evaluación, parece conveniente contar con la participación de los diversos ámbitos o sectores de la comunidad educativa (directivos, profesores en sus diversas funciones, otros profesionales del centro, alumnos y padres) y de elementos externos a la misma (tales como inspectores y otras autoridades académicas, Administración educativa en general, $u$ otras agencias no incluidas en la estructura del centro).

\subsection{INDICADORES DE EFICIENCIA}

La experiencia pone frecuentemente de manifiesto que los resultados que se obtienen en un proyecto educativo pueden tener factores determinantes que ofrecen diversas procedencias. Así, es sobradamente conocida la incidencia que sobre la educación que se adquiere en un centro educativo tiene la familia de origen del alumno; también se reconoce el efecto determinante que el entorno social en que se desenvuelve un alumno puede tener sobre los resultados que se obtengan, e, incluso, el espacio físico en que se encuentra puede, también, repercutir en su rendimiento. Pero, además de los citados factores, otros muchos pueden estar influyendo directa o indirectamente en los resultados.

Esta relación entre factores determinantes o "input" y los resultados obtenidos o "output" es lo constituye la eficiencia de una acción o proyecto educativo. Los indicadores de eficiencia sí tienen en cuenta la relación entre los resultados logrados ("output") y el "input" del propio proyecto. En este sentido, tales indicadores tratan de determinar la adecuada rentabilidad del proyecto, mediante el análisis de costo-resultados y la incidencia del punto de partida (fundamentalmente contexto y recursos disponibles) en los efectos producidos. 
Dentro de estos indicadores de eficiencia podríamos situar la denominada "referencia idiosincrática", en la que se tienen en cuenta las circunstancias que rodean al proyecto. En este sentido, podría considerarse aquí la valoración de las instituciones proveedoras (por ejemplo, nivel de confianza de las instituciones de apoyo presupuestario, logístico, de materiales, etc.). Está claro que la provisión o no de los elementos que conlleva su aportación e, incluso, la forma en que tal provisión se produce son elementos determinantes de un cierto rendimiento o producto educativo.

En definitiva, los indicadores de eficiencia tratan, pues, de determinar si los resultados muestran un elevado grado de "rentabilidad" del proyecto, en el más amplio sentido, que podría también entenderse como "nivel de productividad" o, incluso, "perfil económico" de dicho proyecto. No debe ello estrictamente entenderse, particularmente en el ámbito educativo, como la preocupación por reducir los recursos disponibles, cuanto el interés por hacer más eficaces los que se poseen. De un modo más simple, parece evidente que un incremento de los recursos debiera producir un aumento o mejora de resultados; sin embargo, puede ocurrir que no se produzca tal mejora en dichos resultados o que éstos no mejoren tanto como cabría esperar de la inversión realizada; esto significaría que nos encontramos ante una mala utilización de los recursos o, lo que es lo mismo, un bajo nivel de eficiencia.

Algunos posibles indicadores de eficiencia a los que cabría referirse son los siguientes: optimización de la capacidad formativa de los alumnos; empleo del tiempo, aprovechamiento de recursos humanos, explotación de recursos físicos (inmueble, instalaciones, mobiliario, materiales), utilización de medios económicos, funcionamiento de estructuras organizativas, etc. La coherencia en los niveles deseables de eficiencia exigiría, por ejemplo, que cuando los alumnos poseen una elevada capacidad intelectual o educativa, los resultados que se obtengan con los mismos han de ser elevados. Lo mismo cabría decir cuando un centro o institución posee un cuadro de profesores de elevada cualificación. O cuando se han puesto a disposición de un proyecto de mejora excelentes instalaciones o cuantiosos recursos.

\subsection{INDICADORES DE FUNCIONALIDAD}

Los indicadores de funcionalidad tratan de valorar la idoneidad del proceso de ejecución del proyecto mismo, con independencia de los resultados obtenidos y, en lo posible, los recursos puestos en acción. En todo proceso humano, y particularmente en los de carácter educativo, se produce una relación entre los sujetos que intervienen, creándose un clima interno determinado; en muchas ocasiones, el despertar de relaciones de proximidad emocional y la propiciación de marcos de estímulo positivo constituyen un patrimonio mucho más valioso que los fríos resultados académicos. ¡Cuántas 
veces, por ejemplo, el entusiasmo despertado por un gran profesor en sus alumnos ha sido más determinante para su futuro que la simple acreditación académica recibida!

Es obvio, en todo caso, que la forma en que se lleven a cabo procesos educativos determinados tiene una gran trascendencia formativa. Parece, por tanto, necesario, atender a estos efectos como elementos constitutivos de la valoración de un proyecto educativo; aunque, en ocasiones, resulten difíciles de valorar, el esfuerzo a ello dedicado puede ser muy valioso pues, a través de tal evaluación, podemos detectar actitudes cuya influencia sobre los alumnos participantes en una determinada acción educativa puede ser altamente decisiva.

Entre los posibles indicadores a utilizar para la valoración de la funcionalidad de un proyecto cabe referirse a los siguientes: la coherencia de la realización con la concepción básica del diseño, el respeto a los propósitos generales, la racionalidad y sistematización de los procedimientos empleados, la oportunidad de las estrategias o actividades realizadas, la evolución de la cultura institucional, del clima relacional de los participantes y de su participación en el proceso, el tipo de liderazgo ejercido o el estilo de dirección del proyecto, las relaciones con los clientes internos (personal del centro) y externos (alumnos y padres), etc.

\subsection{INDICADORES DE IMPACTO}

Para completar la evaluación de un proyecto educativo parece conveniente valorar, también, el efecto que fuera del ámbito estricto donde se lleva a cabo la acción educadora tienen los resultados del mismo. Los indicadores de evaluación del impacto pondrán de manifiesto los efectos que un proyecto produce en el ámbito de incidencia de sus resultados, pero con independencia de estos últimos. Para llevar a cabo esta estimación, habrá que contar con la opinión de representantes del entorno físico, social y organizativo del proyecto mismo (en nuestro caso: espacio físico, padres, alumnos, administradores, profesores, otros centros educativos, organizaciones, familia, otros proyectos, etc.).

Pero, además, habrá que tener en cuenta todos aquellos sectores en los que de un modo directo o indirecto tiene algún efecto el producto educativo conseguido (así, habrá que considerar el impacto que se produce sobre el propio ámbito familiar, sobre otros niveles, etapas e instituciones educativas; sobre los sectores laborales y productivos, y sobre el entorno social en general en el que van a situarse los que han participado como implicados en el proyecto de acción educativa). Cabe, por tanto, referirse a la repercusión que la formación lograda por tales alumnos tiene en diferentes ámbitos que siste- 

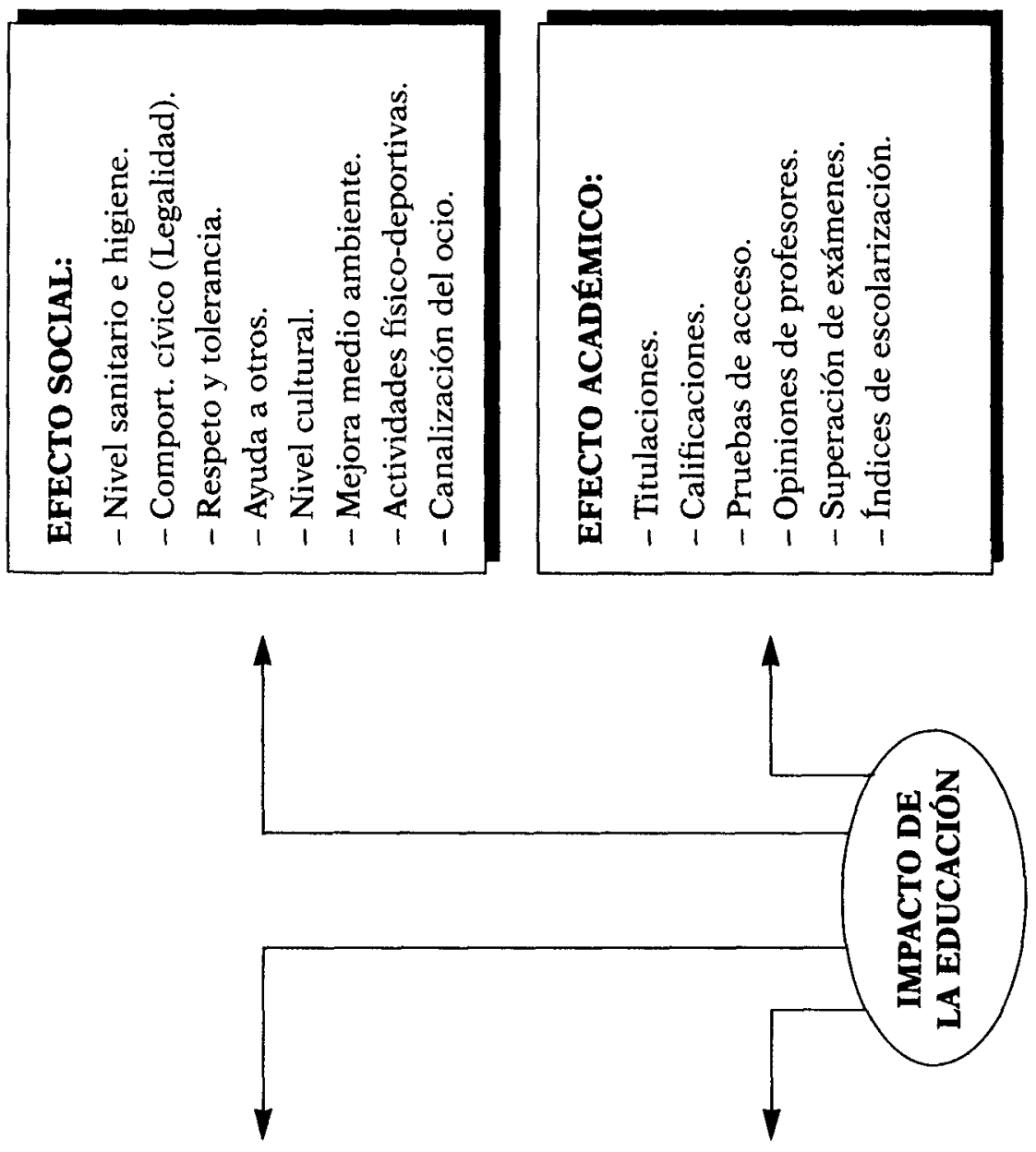

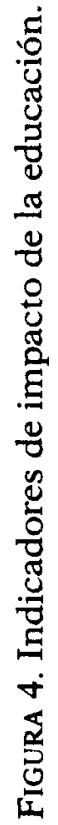
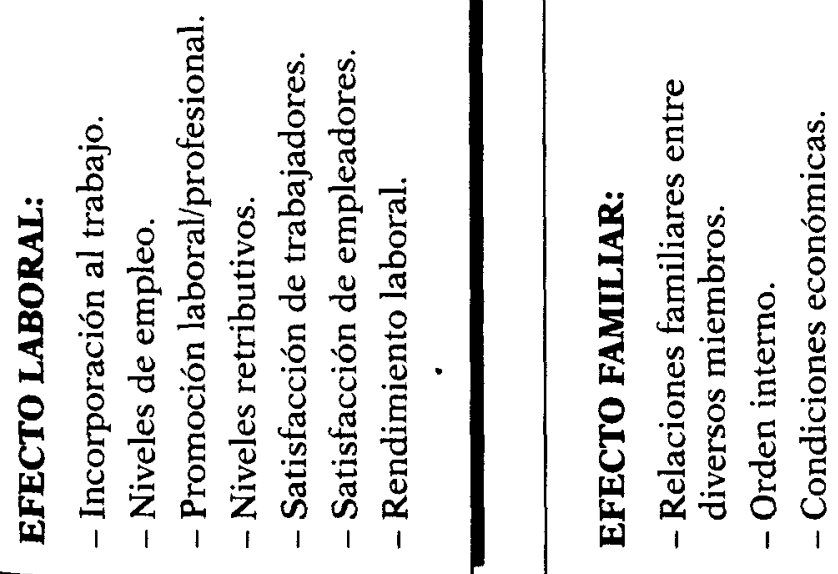
matizamos en torno a los siguientes (Fig. 4): académico, familiar, laboral y social.

En el ámbito académico habremos de referirnos al efecto que sobre estudios o resultados académicos posteriores tiene lo conseguido mediante el proyecto. A estos efectos, partimos del supuesto de que un determinado alumno de un nivel o etapa educativa, además de la formación recibida en uno y otra, suele continuar su formación en estadios posteriores. En último extremo, hoy constituye una realidad generalmente aceptada la necesidad de "el aprendizaje a lo largo de toda la vida" o la "formación permanente".

Esto supuesto, no cabe duda de que la formación que un individuo adquiere en un momento determinado tiene su efecto en la que vaya a adquirir en otro posterior. E, incluso, suele frecuentemente ocurrir que las propias acreditaciones académicas están influenciadas por lo que viene conociéndose como el "expediente académico" acumulado por un alumno hasta ese momento.

En el ámbito familiar nos situaremos dentro del efecto que la preparación lograda por los alumnos tiene sobre su propia familia. Asistimos, en la actualidad, a una acentuación de las relaciones entre las instituciones y proyectos o programas educativos con la familia de la que proceden los alumnos, especialmente cuando éstos se sitúan en los niveles básicos del sistema educativo; estas relaciones se basan en el hecho de que el núcleo familiar tiene una clara e intensa incidencia en el proceso educativo que se lleva a cabo en las instituciones educativas .

Menos tratada, sin embargo, es la incidencia que la propia educación que los alumnos adquieren tiene sobre la familia de los mismos. Pero un planteamiento multidimensional de la acción formadora dentro del paradigma de la calidad total nos lleva a considerar este efecto como derivado naturalmente de la transferencia que la educación tiene sobre este sector de ubicación generalizada del ser humano (Gento, S., 1995). Es obvio que la intensidad y calidad de la educación recibida por los alumnos repercute sobre sus propias familias.

Serán diversos los componentes de la vida familiar sobre los cuales tendrá repercusión la educación; por citar sólo algunos, cabe referirse al clima familiar y a las relaciones entre los distintos miembros; puede, asimismo, mencionarse la incidencia culturizadora que sobre el conjunto de los otros miembros de una familia puede tener la formación de alguno de ellos; y cabe, también, considerar hasta la posible mejora de las condiciones económicas de la familia en cuestión por el efecto que sobre la misma puede tener la educación de sus propios componentes. 
En el ámbito laboral habrá que referirse a la repercusión o efecto que la educación pueda producir en el sector laboral y productivo. Debe reconocerse que esta proyección de la formación fuera del ámbito estrictamente académico ha sido considerada, si acaso, como responsabilidad de los educadores (al menos los de los sistemas formalizados) sólo en los niveles en los que dicha formación se orientaba claramente hacia la formación laboral o profesional. Pero, en todo caso, el seguimiento de la repercusión o impacto real que la educación recibida tenía sobre la ocupación y la producción ha sido generalmente escaso.

Sin embargo, cada vez en mayor medida los responsables de políticas de empleo y aun los propios trabajadores, además de los empresarios, contemplan la necesidad de que la educación considere este necesario impacto, de que lo tenga en cuenta y de que aborde la necesidad de atenderlo convenientemente. A pesar de las dificultades de acceso a un empleo o trabajo fijo en el momento actual, cada vez se pone más de manifiesto que la educación ayuda a lograrlo, a consolidarlo y a mejorarlo. También resulta cada vez más evidente que la formación de trabajadores, empleados y profesionales contribuye en gran medida a incrementar el progreso de los sectores productivos de una determinada comunidad. En qué medida un proyecto educativo contribuye a lograr un efecto satisfactorio en los ámbitos mencionados constituirá el fundamento de la evaluación de impacto en dicho sector.

Finalmente, en el ámbito social habría que considerar el efecto que la educación recibida por los sujetos acogidos por un proyecto educativo puede tener sobre el entorno social en el que continúan conviviendo con sus semejantes. Al igual que en el ámbito familiar, también aquí ha sido profusamente analizada la incidencia que el entorno social (en sus componentes de tipo económico, cultural, etc.) tiene sobre la educación recibida en las instituciones, hasta el punto de considerarse que esta última era desbordada por la anterior.

Pero cada vez es mayor la preocupación por la contribución que la educación, a través de las personas que participan en proyectos educativos, tiene sobre el entorno social en que tales personas se desenvuelven. El desarrollo de una forma de organización predominantemente urbana, en la que afloran numerosos subproductos no deseables, cada vez en mayor grado, reclama la asistencia de la acción educadora para resolver sus problemas. En este sentido, es indudable que el nivel cultural del conjunto social puede verse afectado; pero también ello puede ocurrir en rasgos de dicho conjunto tales como las manifestaciones de convivencia (civismo, respeto, seguridad, etc.), la mejora del medio ambiente y en otros más. Esta responsabilidad, aunque implique un efecto diferido de la acción educativa, ha de tenerse en cuenta, también, en la evaluación de un proyecto educativo. 


\section{PROPUESTA OPTIMIZADORA}

Además de la estimación de resultados, en la fase de evaluación y retroalimentación se formulará una propuesta optimizadora fundamentada en torno al proyecto, basada en los datos recogidos y en las conclusiones a que se haya llegado. Esta propuesta podrá incluir, en su caso: la ratificación (sobre la base del éxito del proyecto), las modificaciones de mejora (a base de la rectificación, supresión u optimización de los aspectos pertinentes), y, en definitiva, la continuidad del proyecto, en su caso, con las matizaciones a que acabamos de referirnos.

La propuesta debe ser oportunamente fundamentada; ello supone que debe procurarse, en lo posible, poner de manifiesto las causas que han determinado resultados satisfactorios, así como las razones que han motivado la aparición de fallos o deficiencias. Algunos de los supuestos replanteados en la propuesta podrían ser los siguientes: reconsideración de la fundamentación ideológico-conceptual, redefinición de la acomodación al contexto, reestructuración del proyecto estratégico en su conjunto, replanteamiento de la metodología de actuación, reelaboración de actividades a llevar a cabo, replanteamiento de los objetivos, mejora de procesos fundamentales, planes sectoriales de mejora, mejoramiento de la cultura institucional (nivel ético, modales y maneras, etc.), provisión de recursos e instrumentos más convenientes, etc.

\subsection{FUNDAMENTACIÓN}

La evaluación no puede ser un fin en sí misma, ni agota el proceso de optimización, aun en el caso de que nos refiramos a la final o postactiva. Muy al contrario, la evaluación ha de tener una finalidad propedéutica: su auténtica utilidad radica en el efecto que sobre un proyecto determinado tiene para mejorarlo. Por tanto, los resultados que la evaluación ponga de manifiesto habrán de interpretarse a la luz de los supuestos que inciden en los mismos y habrán, además, de conducir a unas conclusiones en las que se destaquen aquellos aspectos que por su especial relevancia y significatividad reclaman una actuación sobre los mismos; en definitiva, la evaluación ha de tener en última instancia una intencionalidad formativa o de mejora fundamentada.

También ha de tenerse particularmente en cuenta que la evaluación no puede concebirse estrictamente como un control que se ejerce sobre los responsables de un determinado aspecto o proceso, con el propósito de proponer la utilización de sanciones que se llevan a cabo sobre quienes no han llevado a cabo correctamente sus cometidos; e, incluso, ni siquiera han de contemplarse los resultados de la evaluación como un medio para determinar las recompensas que han de otorgarse a aquellos individuos que se acomodan a determinados parámetros. Ambos planteamientos son extremada- 
mente peligrosos, especialmente cuando poseen una vinculación estrictamente individual, por lo que debe procurarse utilizarlos con extrema cautela. En todo caso, los reconocimientos parece más conveniente que se realicen hacia colectivos o grupos de personas que trabajan en un determinado proyecto o consecución de un determinado objetivo, y han de manejarse con acentuada precaución.

Lo que sí resulta especialmente defendible dentro de un enfoque de calidad es, insistimos, el aprovechamiento de los resultados de la evaluación para actuar sobre un proyecto determinado y sobre los elementos que inciden en uno u otro, y ello con el propósito de optimización en la medida de lo posible. Pero, para que la propuesta concreta de actuación para ocasiones sucesivas tenga solidez y resulte incontrovertible en alto grado, habrá de estar convenientemente fundamentada.

Dicha fundamentación se basará en la manifestación evidente de los resultados de la evaluación, en la interpretación que se haga de los mismos y en el enunciado de las conclusiones. Pero la evidencia de los datos que se utilicen deben estar suficientemente respaldados por comprobaciones que pongan de relieve la consistencia científica de los datos sobre los que se basan las deducciones que se realizan. Además de ello, sería oportuno contar con la intervención de los propios implicados en los hechos o procesos, con el fin de garantizar su aquiescencia en tales deducciones

La utilización concurrente de los diversos procedimientos de evaluación ya descritos facilitará la aquiescencia de los implicados en los aspectos evaluados; pero, además, su participación ha de estar presente en el análisis de datos, en su interpretación y en las conclusiones. E, incluso, conviene contar con dicha intervención en la priorización de posibles acciones de mejora que se lleven a cabo tras la evaluación; en dicha priorización podrían incidir, junto a la evidencia científicamente contrastada, otros criterios no estrictamente implícitos en la evaluación, pero cuya importancia puede hacer necesaria su consideración. Con todo ello, podrá llegarse a la formulación de propuestas de mejora, que podrán girar en torno a los tres tipos siguientes: de reafirmación de aciertos, de corrección de deficiencias y de formulación de nuevas iniciativas.

\subsection{REAFIRMACIÓN DE ACIERTOS}

Una evaluación de calidad no ha de orientarse exclusivamente hacia la búsqueda de los errores o imperfecciones, sino que tratará de poner en evidencia si los planteamientos, los procesos y los productos son los más adecuados para las metas que pretenden lograrse, supuesto que éstas se acomodan a los marcos institucionales y personales en los que se produce el fenómeno educativo concreto. 
La evaluación, así entendida, pondrá de manifiesto que algunos de los supuestos analizados aparecen evidente y consistentemente como aciertos o logros reales. Tales aspectos deben ser puestos de relieve, no solamente durante la evaluación propiamente dicha, sino que han de aparecer también en la propuesta optimizadora que de ella se derive. Sin perjuicio de la apetencia, implícita en el paradigma de calidad total, por seguir mejorando los aciertos (puesto que cualquier intervención del ser humano puede mejorarse), los que aparezcan consolidados y los que resulten indiscutibles deben ser asumidos como un patrimonio de la institución, del proyecto o del equipo de personas responsables de la actuación educativa de que se trate. Además de ello, ha de proponerse la consolidación de los mismos.

Claro que los aciertos podrán referirse a ámbitos diversos implícitos en el proyecto específico; en algún caso, tal vez puedan hacer relación con los medios puestos a disposición para el diseño, para la realización o hasta para la valoración de determinados aspectos; en otros casos, los logros podrán estar en los diseños mismos, que se han llevado a cabo de modo conveniente; podrán, también, aparecer aciertos en la realización de procesos de calidad para el logro de objetivos o metas de tal condición; y, por supuesto, los propios resultados podrán ser también considerados como adecuados en términos absolutos y, sobre todo, en función del "input" (contexto, disponibilidad de recursos, viabilidad de actividades, etc.). Estos aciertos pasarán a formar parte del patrimonio de calidad de una institución o grupo.

\subsection{CORRECCIÓN DE DEFICIENCIAS}

La evaluación podrá, también, poner de manifiesto que determinados supuestos, procesos o resultados no alcanzaron los niveles deseables de calidad. Tal como hemos señalado, resulta particularmente necesario que la evidencia de las deficiencias o imperfecciones sea absolutamente incontrovertible; e, incluso, que sea asumida como tal por los propios protagonistas, lo que no implica una valoración peyorativa de su implicación, sino un aprendizaje que puede ser altamente de utilidad para plantear su mejora. Resulta obvio que la asunción de dichas imperfecciones será más fácilmente lograda si no existe un efecto directo de las mismas para sancionar a los que hayan podido, en su caso, producirlas; la intencionalidad debe ser claramente optimizadora, que no sancionadora de deméritos ni de méritos.

En la propuesta de optimización del proyecto deberá, por tanto, incluirse la eliminación, en lo posible, de los errores o deficiencias o, al menos, la disminución de los mismos. Pero, para que puedan en ocasiones sucesivas mejorarse tales aspectos, será necesario que se enuncien con claridad y objetividad, de modo que no den lugar a dudas o a diferentes interpretaciones. De igual modo, las propuestas de corrección de deficiencias indicarán, en lo posible, las causas determinantes de las mismas y, en cuanto lo permitan las 
circunstancias, habrán de sugerir la forma de eliminarlas o reducirlas. Cuando este último aspecto no pueda ser propuesto de modo concreto o no pueda ser desarrollado con detalle suficiente, se sugerirán vías de ejecución o, en último extremo, fuentes o referencias para estudiar la problemática en cuestión y para encontrar la información que permita plantear convenientemente su mejora.

\subsection{NUEVAS INICIATIVAS}

La evaluación del proyecto educativo es, en definitiva, la valoración de un proyecto de innovación para determinar la mejora de las actuaciones que implica; puede, por tanto, entenderse como un estudio fundamentado y veraz o, en cierto modo, como una investigación en la acción. En este sentido, al igual que ocurre en cualquier estudio o investigación, la realización del mismo no solamente permite extraer evidencias y conclusiones estrictamente derivadas de la hipótesis que desencadena la indagación; además de ello, suele suscitar otros campos de análisis o de tratamiento que, si bien no están expresamente incluidos en el enunciado de la hipótesis o en el planteamiento de partida, guardan relación con el proyecto.

De la misma forma, el análisis e interpretación de los datos de la evaluación del proyecto educativo puede sugerir campos de tratamiento y, en definitiva, de mejora, no estrictamente incluidos entre los aciertos a consolidar o las deficiencias a rectificar. Se trataría, más bien, de otro tipo de iniciativas cuya propuesta y posterior puesta en acción puede contribuir a mejorar el mencionado proyecto o alguno de sus aspectos.

Algunas de las iniciativas que se sugieran pueden requerir un estudio más en profundidad de su autenticidad y solidez, y pueden exigir la búsqueda del consenso de los implicados antes de asumirlas con firmeza y de proponer acciones concretas. Pero, en todo caso, resulta conveniente propiciar la oportunidad de que se formulen dichas iniciativas que, en definitiva, pueden suponer la extensión del paradigma de la calidad total en educación e, incluso, la afloración de otros paradigmas de visión, análisis y mejora de la realidad educativa. 


\section{BIBLIOGRAFÍA}

ALVIRA, F. (1991). Metodología de la Evaluación de Programas. Madrid: Centro de Investigaciones Sociológicas.

CARDONA, J. (1994). Metodología Innovadora de Evaluación de Centros Educativos. Madrid: Sanz y Torres.

CASTILlo, S. y GENTO, S. (1995). "Modelos de evaluación de programas educativos". MEDINA, A. y VILLAR, L.M. Evaluación de Programas Educativos, Centros y Profesores. Madrid: Universitas.

COLÁS, M.P. y REBOLLO, M.A. (1993). Evaluación de programas. Sevilla: Kronos

LINDZEY, G. y ARONSON, E. (edits.). Handbook of Social Psychgology. New York: Random House.

CRONBACH, L.J. (1980). Toward Reform of Program Evaluation: Aims, methods and Institutional Arrangements. San Francisco: Jossey-Bass.

CRONBACH, L.J. (1982). Designing Evaluations of Educational and Social Programs. San Francisco: JosseyBass.

FERRÁNDEZ, A. y PUENTE, J.M. (1991). Material Autodidacta de Formación de Formadores de Adultos. Madrid: Fondo de Promoción de Empleo.

FITZ-GIBBON, C.T. (1987). How to Design a Program Evaluation. London: Sage.

HERMAN, J.L. (1987). Program Evaluation Kit. Evaluator's Handbook. London: Sage.

GARANTO, J. (1989). "Modelos de evaluación de programas educativos". ABARCA, P. (coord.). La Evaluación de Programas Educativos. Madrid: Escuela Española.

GENTO, S. (1989). Formación y Actuación Profesional de los Profesores de Inglés en EGB. Madrid: Universidad Complutense.

GENTO, S. (1992). "Formación cultural básica de personas adultas". UNED. Formación de Educadores de Adultos II. Madrid.
GENTO, S. (1994 a). Participación en la Gestión Educativa. Madrid: Santillana.

GENTO, S. (1994 b). "Técnicas y estrategias didácticas en educación de personas adultas". SANZ, F. (Coord). La Formación en Educación de Personas Adultas. Madrid: UNED, pp. 859-918.

GENTO, S. (1994 c). "Técnicas, procedimientos e instrumentos de evaluación para la Escala de Evaluación Diagnóstica". CARDONA, J. Metodología Innovadora de Evaluación de Centros Educativos. Madrid: Sanz y Torres.

GENTO, S. (1995). Instituciones Educativas para la Calidad Total. Madrid: La Muralla.

KEEGAN, D. (1993). Theoretical Principles of Distance Education. London: Routledge.

KING, J. (1987). How to Assess Program Implementation. London: Kogan.

MARCELO, C. (1996). "Evaluación de las innovaciones educativas". MACHIO, A.; MARCELO, C., y MURILLO, P. (Coords.). Jomadas sobre Proyectos de Innovación. Alcalá de Guadaira (Sevilla): C.E.P., pp. 153 - 223.

MARTINEZ, J. (1993). Proyectos Curriculares y Práctica Docente. Sevilla: Díada.

MEDINA, A. ( 1980). Didáctica e Interacción en el Aula. Madrid: Cincel.

MEDINA, A. y DOMINGUEZ, C. (1995). Enseñanza y Curriculum para la Formación de Personas Adultas. Madrid: Ediciones Pedagógicas.

MEDINA, A. y GENTO, S. (1991). "Configuración del diseño curricular en educación de adultos". MEDINA, A. (Coord). Formación de Educadores de Adultos. Madrid: UNED (PFP).

MEDINA, A. y GENTO, S. (1996). "Diseño y valoración del proyecto curricular en educación secundaria para personas adultas". MEDINA, A. y GENTO, S. (Coords.). Formación de Formadores en Educación Secundaria para Personas Adultas. Madrid: UNED. 
MEDINA, A. y VILLAR, L.M. (1995). Evaluación de Programas Educativos, Centros y Profesores. Madrid: Universitas.

PALUMBO, D. (1987). The Politics of Program Evaluation. Newbury Park: Sage.

PÉREZ, G. (1995). "La educación permanente de adultos: perspectivas internacionales". DEPARTAMENTO DE TEORÍA. Segundas Cuestiones Actuales sobre Educación. Madrid: UNED, pp. 255-74.

PÉREZ, R. (1995). "Evaluación de programas educativos". MEDINA, A. y VILLAR, L.M. Evaluación de Programas Educativos, Centros y Profesores. Madrid: Universitas, pp. 73-106.

PETERS, T.J. \& WATERMAN, R.H. (1993). In Search of Excellence. New York: Harper Collins (1st. edition, 1982).

PLANTE, J. (1994). Évaluation de Programme. Laval (Canada): Université Laval.

POSAVAC, E. y CAREY, R. (1989). Program Evaluation. Englewood Cliffs (NJ): Prentice Hall.
PROVUS, M. (1971). Discrepancy Evaluation for Educational Program Improvement and Assessment. Berkeley (Ca.): McCutchan.

SANTOS, M. A. (1990). Hacer Visible lo Cotidiano: Teorías y Práctica de la Evaluación de Centros Escolares. Madrid: Akal.

SCHEERENS, J. (1992). Effective Schooling. London: Cassell.

SCHEIRER, M.R. y RENSO, E.L. (1983). "Measuring the degree of Program Implementation: a methodological review". Evaluation Review, 7, pp. 559-653.

URIARTE, K. (1996). "Evaluación y estrategia de cambio de un centro educativo". ICE-UNIVERSIDAD DE DEUSTO. Dirección Participativa y Evaluación de Centros. Bilbao: Mensajero, pp. 717-727.

VICENTE, P. DE (1994). "Estrategias y competencias de enseñanza práctica". VILLAR, L.M. y VICENTE, P. de. Enseñanza Reflexiva para Centros Educativos. Barcelona: PPU, pp. 211238.

\section{RESUMEN}

Partiendo de la consideración de que la evaluación es ineludible a cualquier proyecto educativo que aspire a ser de auténtica calidad, se ofrece aqui un marco de referencia cuya aplicación a la realidad concreta dependerá de la decisión de los implicados en el propio proyecto. Se destaca, como requisito previo, que la evaluación a que aquí nos referimos no sólo ha de realizarse a partir de la decisión de los propios protagonistas, sino con su intervención directa; ello no obsta a que se acuda al asesoramiento y estimación de jueces expertos que ayuden a encontrar la evidencia potenciadora de la mejora.

La evaluación de un proyecto de esta naturaleza se plantea en torno a tres fases fundamentales, a saber: la validación preactiva (en la que se trata de 
poner de relieve la adecuación entre el proyecto diseñado y el modelo teórico aplicable al mismo); la evaluación interactiva (en la que se busca la idoneidad de la puesta en acción, contando para ello con la opinión concurrente de los agentes fundamentales y de otros que puedan servir de base para el contraste); y la valoración postactiva (en la que se plantea la estimación de los resultados tras la puesta en acción del proyecto). Además de ello, se propone la explotación de las evidencias logradas en la propuesta optimizadora que, suficientemente fundada, sugerirá la reafirmación de los aciertos, la posible corrección de deficiencias, y la asunción de nuevas iniciativas.

Palabras clave: Autoevaluación, Coevaluación, Eficacia, Eficiencia, Evaluación interactiva, Funcionalidad, Heteroevaluación, Impacto (del producto educativo), Propuesta optimizadora, Técnicas de evaluación, Triangulación, Validación preactiva, Validez de apariencia o aparente, Validez de constructo, Validez de contenido, Validez de contraste, Valoración postactiva.

\section{ABSTRACT}

By assuming that evaluation is impending for any educational project tending to be of true quality, it is offered here a reference framework whose applicability to a particular situation will be decided by the people involved in the project. It is stressed that, as a necessary condition, the evaluation here proposed will be implemented when the involved protagonists decided it and, furthermore, they will be the main agents of such evaluation. Nevertheless, it is accepted the contribution of external experts who help to find out the evidence necessary to promote improvement.

The evaluation of such project is proposed here throughout three main stages: the preactive validation (in order to study the accommodation between the designed project and the conceptualised theoretical model); the interactive evaluation (to look for the right implementation, according to opinions of protagonists and other contrasting experts); and the postactive assessment (to estimate the obtained results produced by the educational project). Apart from that it is suggested here the opportunity of setting up the improvement proposal that, based enough, will include the confirmation of success, the possible rectification of deficiencies and the assumption of new initiatives. 
Key words: Co-evaluation, Content validity, Construct validity, Contrast validity, Efficacy, Efficiency, External evaluation, Evaluation techniques, Face validity, Functional implementation, Impact (of educational product), Improvement proposal, Inter-active evaluation, Post-action evaluation, Pre-action validity, Self-evaluation (internal evaluation), Triangle evaluation. 